\title{
Forum to advance trials for AIDS therapies
}

Washington. US drugs companies and federal agencies are to collaborate in a new forum that will try to agree on the design and funding of the clinical trials that are needed to optimize combination therapies for treating AIDS.

AIDS activists and organizations that pay for health care will also be represented on the 40-member Forum for Collaborative HIV Research, which was announced by Vice-President $\mathrm{Al}$ Gore on 2 August.

The forum will address increasing concern about how AIDS researchers can keep track of the efficacy of different therapies as drugs arrive on the market and are used in various combinations. Some new drugs have been approved by the US Food and Drug Administration under an accelerated approval procedure, which means that they reach the market before the completion of normal, three-phase clinical trials.

The idea of a forum on AIDS research issues arose from an AIDS summit at the White House last December and a meeting last February between Gore and the chief executives of drug companies. The details were worked out in meetings organized in

\section{German groups debate ethics rules}

Munich. The German section of the Pugwash Conferences on Science and World Affairs has criticized a report by the research society, the Deutsche Forschungsgemeinschaft (DFG), calling for a relaxation of the strict regulations under which German scientists have to operate, particularly in biotechnology (see Nature 380, 469; 1996).

In a hard-hitting statement published earlier this summer, the Vereinigung Deutscher Wissenschaftler (VDW) calls the DFG report "self-righteous and self-pitying". The real threat to research is not over-regulation, argues the VDW, but the increasing tendency to respond to "pressures to answer short-term economic or medical needs".

VDW was founded in 1959 by nuclear physicists opposed to nuclear armament, including Max Born, Otto Hahn, Werner Heisenberg and Max von Laue.

The DFG report, says the VDW, reveals a lack of understanding by research scientists of public concern about aspects of science such as the use of animals in experiments and genetic engineering. Yet "research is paid for by society and therefore is also accountable to society", it argues.

One strong point of disagreement concerns two articles on fundamental rights in the German constitution that appear to conflict when applied to research on human embryos. One article guarantees the freedom of research, the other the right to life and freedom from injury.

The DFG had argued that, when research aims to protect life in the long term, the freedom of research article should take precedence. But the VDW argues that there should be no exceptions to the primacy of the right to life.

As new developments in biotechnology and embryo research impinge directly on this right, says the VDW, public fears are legitimate and should not simply be ignored. It calls for either formal public hearings or referenda on "complex moral problems" such as embryo research before further DFG projects in such controversial areas are selected for funding.

Such important decisions should not be left to "elitist ethics commissions", says Hans-Peter Bull, professor of law at the University of Hamburg, a co-author of the VDW position paper. The paper also says that researchers should not be exempt from legal liability if applications of their work go wrong.

The DFG has been fighting for years against the bureaucratic obstacles facing biomedical researchers, with some recent successes. So far it has responded cautiously to this attack from within the academic community. At its annual meeting in Leipzig in June, DFG president Wolfgang Frühwald gave a formal welcome to the document, saying that the aim of its report had been to stimulate such dis-

Frühwald: welcomed cussion.

Along with Hubert Markl, the new president of the Max Planck Society, Frühwald has offered to conduct an open debate on the subject.

But Rüdiger Wolfrum, director of the Max Planck Institute for International Law in Heidelberg, co-author of the DFG report, is sceptical of the VDW's demand for more participation by the lay public in complicated scientific decisions. "The complexity of gene technology does not lend itself to the formulation of questions that can be answered with a simple yes or no," he says.

Wolfrum also rejects the idea of imposing legal liability on basic researchers in the event of undesirable consequences of research applications. Apart from the principle involved, the gap between basic research and the development of products is so wide that it would be impossible to prove guilt.

Quirin Schiermeier
Washington by the Keystone Center. As the promise of new combination therapies emerged, the meetings agreed that the forum should concentrate on the question of the trials.

Assessing the combinations will require new trial designs, which may, for example, have to accommodate the likelihood that patients will change therapy in mid-trial.

The issue of who should pay for such trials is unresolved. Government agencies and drugs companies both hope that the health-care providers will help to finance them. These providers are facing tough choices and huge bills as patients try to move on to combination therapies, which cost up to $\$ 25,000$ a year.

Tony Fauci, director of the National Institute of Allergy and Infectious Diseases (NIAID) and a forum member, says that the body will "serve as a venue where people can identify gaps that exist" in planned trials. It will not have the power to agree on the financing of trials, but will serve as a "catalyst for interaction" between different parties.

NIAID has two programmes for conducting clinical trials, the AIDS Clinical Trials Group and the Community Program for Clinical Research on AIDS, which receive $\$ 130$ million a year. But these programmes are not going to pay for the large-scale trials now needed.

The drug companies will not pick up the full cost either, because they do not need the trials to obtain approval for their therapies. Linda Distlerath of Merck, another forum member, says it is "unlikely that any entity can do [the trials] on their own".

The trials "are going to look different from trials we've seen in the past", says forum member David Barr of the Gay Men's Health Crisis, a New York-based AIDS advocacy group. "Everyone realizes this is going to be difficult, but we've got to make an attempt."

The trials will have to decide not just the efficacy of different combinations, but also the best time for physicians to switch from one regimen to another, and to withdraw ineffective therapies.

The trials will aim to provide information for physicians on the treatments that they should be prescribing. Just as important, they will inform health-care providers including the public Medicaid programme, managed-care organizations and private health insurance companies - about which treatments they should be prepared to pay for.

The forum is in the process of finding a headquarters, hiring a small staff and raising funding, which is expected to come from both public and private sectors. It will start its meetings next month.

Colin Macilwain 